\title{
SELETIVIDADE E DOSE DE INJÚRIA ECONÔMICA DE NICOSULFURON APLICADO EM DIFERENTES ESTÁDIOS DE DESENVOLVIMENTO DA CULTURA DO MILHO
}

\author{
SELECTIVITY AND RATE OF ECONOMIC INJURY OF NICOSULFURON \\ ON CORN TREATED AT DIFFERENT GROWTH STAGES
}

\author{
Vitor Spader $^{1}$ Ribas Antonio Vidal ${ }^{2}$
}

RESUMO

A tolerância de plantas de milho ao herbicida nicosulfuron é variável em função dos estádios de desenvolvimento da cultura. Um experimento foi conduzido a campo, na EEA-UFRGS, em Eldorado do Sul, com os objetivos de avaliar a seletividade de nicosulfuron aspergido nos diferentes estádios de desenvolvimento vegetativo do milho e com diferentes doses do herbicida e de verificar a resposta econômica da fitotoxicidade do produto na cultura. O milho híbrido AG501, tolerante ao nicosulfuron, foi implantado no sistema de semeadura direta numa área com controle prévio das plantas daninhas com herbicida pré-emergente. Os tratamentos foram organizados num esquema fatorial representado por doses de nicosulfuron $\left(0, \quad 60 \quad e \quad 80 \mathrm{~g} \quad \mathrm{ha}^{-1}\right)$ e pelos estádios de desenvolvimento vegetativo do milho $\left(V_{3}, V_{6}\right.$ e $V_{9}$, indicando 3,6 e 9 folhas expandidas, respectivamente). $O$ delineamento experimental foi o de blocos casualizados com quatro repetições. A seletividade do nicosulfuron para a cultura do milho diminui a partir do estádio de 6 folhas expandidas $\left(V_{6}\right)$ e com o incremento da dose além de $60 \mathrm{~g} \mathrm{ha}^{-1}$. A dose de injúria econômica, ou seja, a dose de nicosulfuron no qual o benefício do controle de ervas se iguala à perda de rendimento de grãos devido a injúria à cultura se reduz com a diminuição do dano causado pelas infestantes e com o aumento do preço da cultura.

Palavras-chave: estádio de desenvolvimento, milho, nicosulfuron, seletividade.

\section{SUMMARY}

The tolerance of the corn crop to the herbicide nicosulfuron depends on the crop growth stage. An experiment was conducted in Eldorado do Sul, RS, Brazil, to evaluate the selectivity of nicosulfuron applied at different rates on corn and at different growth stages, and also to estimate the economic impact of the crop injury caused by the herbicide. The corn hibryd AG 501 was sowed on a no-till system where the weed control was performed with preemergence herbicides. Treatments tested were combinations of the nicosulfuron rates $(0,60$ and $80 \mathrm{~g}$ $\left.h a^{-1}\right)$ with corn growth stage $\left(V_{3}, V_{6} e V_{9}\right)$. Nicosulfuron selectivity decreases after the corn crop reaches the six leaf stage, and with herbicide rates superior to $60 \mathrm{~g} \mathrm{ha}^{-1}$. The rate of economic injury, that is, the herbicide rate in which the benefit of the weed control is equivalent to the yield loss due to weed competition, reduces with the reduction of the impact of the weed on the crop, and with increased corn price.

Key words: corn, nicosulfuron, selectivity.

\section{INTRODUÇÃO}

Entre os principais herbicidas pósemergentes utilizados atualmente na cultura do milho destaca-se o nicosulfuron, do grupo químico das sulfoniluréias. Os herbicidas deste grupo inibem a acetolactato sintase (ALS), a primeira enzima comum à rota de biossíntese dos aminoácidos de cadeia ramificada, valina, leucina e isoleucina, em plantas e microrganismos (ASHTON \& MONACO, 1991; ANDERSON et al., 1998).

A seletividade dos herbicidas sulfoniluréias para as culturas baseia-se nas diferentes taxas de metabolização dos mesmos pelas plantas (SWEETSER $\boldsymbol{e}$ a al., 1982; OBRIGAWITCH et al., 1990; CAREY et al., 1997) e nas velocidades

\footnotetext{
${ }^{1}$ Engenheiro Agrônomo, Aluno do Curso de Mestrado no Programa de Pós graduação em Fitotecnia, Universidade Federal do Rio Grande do Sul (UFRGS), CP 776, 91501-970, Porto Alegre, RS.

${ }^{2}$ Engenheiro Agrônomo, PhD., Professor do Departamento de Plantas de Lavoura, Faculdade de Agronomia, UFRGS. E-mail: emarch@ccr.ufsm.br. Autor para correspondência.
} 
de absorção e translocação nos vegetais. Espécies tolerantes detoxificam rapidamente estes herbicidas, transformando-os em compostos não fitotóxicos pela ação do citocromo $\mathrm{P}_{450}$ monoxigenase, em reações de hidroxilação e glioxilação (FONNE-PFISTER $\boldsymbol{e t}$ al., 1990). Plantas de milho metabolizaram $90 \%$ do nicosulfuron absorvido pelas folhas, enquanto plantas de Sorghum halepense não metabolizaram o herbicida (OBRIGAWITCH et $\boldsymbol{a l} .$, 1990). Plantas de trigo metabolizaram $97 \%$ do chlorsulfuron absorvido, enquanto plantas de beterraba metabolizaram apenas $5 \%$ desse herbicida (SWEETSER et al., 1982).

Híbridos considerados tolerantes ao nicosulfuron podem apresentar sensibilidade diferencial, dependendo do estádio de desenvolvimento da planta, do ambiente e da dose utilizada (MORTON \& HARVEY, 1992; SIEGELIN, 1993; GUBBIGA et al., 1995). Na maioria dos híbridos, a tolerância é mais acentuada nos estádios iniciais de desenvolvimento. Com duas a três folhas expandidas (estádios de desenvolvimento $V_{2}$ e $V_{3}$ ), o milho mostra-se mais tolerante ao nicosulfuron do que nos estádios $\mathrm{V}_{6}$ a $\mathrm{V}_{8}$ (McMULLAN \& BLACKSHAW, 1995). Da mesma forma, nicosulfuron, aplicado na dose de $75 \mathrm{~g} . \mathrm{ha}^{-1}$ em milho nos estádios de desenvolvimento $\mathrm{V}_{3}$ a $\mathrm{V}_{5}$, não reduziu o rendimento de grãos (SIEGELIN, 1993). Entretanto, quando aplicado em plantas nos estádios $\mathrm{V}_{6}$ a $\mathrm{V}_{9}$, o rendimento de grãos da cultura foi reduzido com apenas $19 \mathrm{~g} \cdot \mathrm{ha}^{-1}$ do herbicida (SIEGELIN, 1993; SWANTON et al., 1996). Plantas de milho doce submetidas ao tratamento com 50g.ha ${ }^{-1}$ de nicosulfuron nos estádios de desenvolvimento $\mathrm{V}_{5}$ a $\mathrm{V}_{7}$ apresentaram severos sintomas de injúria, enquanto aquelas tratadas com 25g.ha- ${ }^{-1}$, nas mesmas épocas, foram pouco afetadas pelo herbicida (SULLIVAN \& BOUW, 1997). O híbrido de milho Cargil 505 não apresentou redução do rendimento de grãos quando aspergido com nicosulfuron em doses variando entre 40 e $80 \mathrm{~g} \cdot \mathrm{ha}^{-1}$ nos estádios de desenvolvimento $\mathrm{V}_{5}$ a $\mathrm{V}_{7}$ (FAHL \& CARELLI, 1997).

Em condições de déficit hídrico, as plantas reduzem a degradação do herbicida e mantêm o produto absorvido na forma ativa, afetando a enzima ALS, com conseqüente injúrias nos tecidos. Em condições de alta temperatura do ar, aumenta a absorção, a translocação e a acumulação de nicosulfuron em plantas de Erytrigia repens (BRUCE et al., 1996), mas também aumenta a inativação metabólica do herbicida em plantas de milho (FAHL \& CARELLI, 1997).

Normalmente, a decisão de aplicação dos herbicidas é tomada de forma empírica, com base nas observações visuais da área. Teoriza-se que a tomada de decisão para controle de plantas daninhas deveria ser baseada em fatores biológicos e econômicos. Esses fatores são englobados no conceito de nível de dano econômico, definido como a densidade limite de plantas daninhas, a partir da qual ocorre danos à cultura numa magnitude que justifique economicamente a aplicação do herbicida pós-emergente na dose recomendada (DEEN $\boldsymbol{e t} \boldsymbol{a l}$., 1993). O nível de dano econômico de Brachiaria plantaginea na cultura do milho se situa entre 1 e 10 plantas $/ \mathrm{m}^{2}$ (SPADER, 2000). Nessas baixas densidades, é reduzido o impacto econômico das plantas daninhas sobre a cultura. Como a injúria do herbicida à cultura pode reduzir o seu rendimento de grãos, é importante conhecer o potencial de dano que o herbicida em questão poderá oferecer à cultura, nas condições em que será aplicado e, assim, possibilitar a tomada de decisão com maior segurança sobre a viabilidade econômica do controle de plantas daninhas.

Nesse trabalho, avalia-se o conceito de dose de injúria econômica (DIE), definida como a máxima dose a ser utilizada do herbicida, na qual o benefício do controle de plantas daninhas pelo menos se iguala à perda de rendimento de grãos causada pela fitotoxicidade à cultura. Assim, os objetivos deste trabalho foram avaliar a seletividade de nicosulfuron aspergido em milho em diferentes estádios de desenvolvimento vegetativo e determinar a dose de injúria econômica desse herbicida na cultura.

\section{MATERIAL E MÉTODOS}

O experimento foi conduzido a campo durante a estação de crescimento 1998/99, em área da Estação Experimental Agronômica da Universidade Federal do Rio Grande do Sul, localizada em Eldorado do Sul, RS. O solo da área experimental é classificado como argissolo, com $380 \mathrm{~g} / \mathrm{kg}$ de argila, $\mathrm{pH}$ em água 5,8, matéria orgânica $22 \mathrm{~g} / \mathrm{dm}^{3} ; 8 \mathrm{mg} / \mathrm{dm}^{3}$ de fósforo e $6,6 \mathrm{mmol}_{\mathrm{c}} / \mathrm{dm}^{3} \mathrm{de}$ potássio.

O milho híbrido AG 5011, tolerante ao nicosulfuron, foi semeado no dia 8 de outubro de 1998, no sistema de semeadura direta, em sucessão à aveia preta (Avena strigosa). A adubação do milho foi realizada objetivando-se a produtividade de $12 \mathrm{t} \mathrm{ha}^{-1} \mathrm{e}$ foi feita nas linhas de semeadura com 600kg.ha- ${ }^{-1}$ da fórmula NPK 5-20-20. Realizou-se adubação nitrogenada de cobertura com uréia na dose de 100 e $150 \mathrm{~kg}$ de $\mathrm{N} \mathrm{ha}^{-1}$ aos 20 e 40 dias após a emergência (DAE), quando o milho se apresentava nos estádios $V_{4}$ e $V_{8}$ (quatro $e$ oito folhas 
completamente expandidas), respectivamente. $\mathrm{O}$ controle de plantas daninhas foi realizado com herbicidas pré emergentes (atrazine + metolachlor nas doses de $700+1050 \mathrm{~g} \cdot \mathrm{ha}^{-1}$ ), aplicados com pulverizador tratorizado. As plantas daninhas que emergiram durante o ciclo do milho foram eliminadas com capinas.

Os tratamentos foram organizados num esquema fatorial. $\mathrm{O}$ fator $\mathrm{A}$ representou as doses do herbicida nicosulfuron $\left(0 ; 60\right.$ e $\left.80 \mathrm{~g}^{-h^{-1}}{ }^{-1}\right)$, e o fator B, os estádios de desenvolvimento vegetativo do milho $\left(\mathrm{V}_{3}, \mathrm{~V}_{6}\right.$ e $\left.\mathrm{V}_{9}\right)$. O delineamento experimental foram blocos casualizados, com quatro repetições. O tamanho das unidades experimentais foi $8 \times 3,2 \mathrm{~m}$, contendo quatro fileiras de milho, espaçadas de $0,80 \mathrm{~m}$ e com 5,6 plantas por metro de fileira, perfazendo população de 70.000 plantas de milho ha $^{-1}$ após desbaste, realizado aos 10 DAE. As aplicações do herbicida foram realizadas com pulverizador costal pressurizado com gás carbônico $\left(\mathrm{CO}_{2}\right)$, equipado com barra de $2,0 \mathrm{~m}$ e bicos tipo leque 80.03 , mantendo-se a pressão constante em $150 \mathrm{kPa}$, e volume de calda de 220L.ha ${ }^{-1}$. A temperatura $\left({ }^{\circ} \mathrm{C}\right)$ e a umidade relativa do ar $(\%)$, durante cada aplicação, foram de 28 e 72, respectivamente, no estádio $\mathrm{V}_{3}, 25$ e 80 no estádio $\mathrm{V}_{6}$ e de 27 e 75 no estádio $\mathrm{V}_{9}$. Aos cinco dias após a semeadura, aplicou-se $20 \mathrm{~mm}$ de água via irrigação por aspersão. Efetuou-se irrigação por aspersão, nos períodos em que a precipitação pluvial foi insuficiente para suprir a exigência da cultura, até o estádio de maturação fisiológica do milho.

Avaliou-se a estatura de planta, número de espigas por planta, número de grãos por espiga, massa de mil grãos e rendimento de grãos de milho. As avaliações foram feitas nas duas linhas centrais, descontando-se $1,0 \mathrm{~m}$ em cada extremidade, perfazendo $9,6 \mathrm{~m}^{2}$ de área útil.

Os dados foram submetidos à análise de variância pelo teste $\mathrm{F}$, e a comparação dos resultados entre os estádios de desenvolvimentos $\left(\mathrm{V}_{3}, \mathrm{~V}_{6}\right.$ e $\left.\mathrm{V}_{9}\right)$ foi realizada pelo teste de Tukey, ao nível de $5 \%$ de probabilidade do erro. Aplicou-se análise de regressão para a comparação entre doses do herbicida. As declividades das curvas (D) divididas pela intercecção no eixo Y (A) ajustadas em cada época de aplicação foram utilizadas para estimar a dose de injúria econômica (DIE) do herbicida nicosulfuron aplicado em pós emergência no milho, conforme a Equação 1 (SPADER, 2000).

$$
\mathrm{DIE}=\mathrm{DE} /[10000 .(\mathrm{D} / \mathrm{A}) .(\mathrm{P} / 1000)] \quad \text { (Equação 1) }
$$

Para o cálculo do DIE, considerou-se o preço do milho $(\mathrm{P})$ variando na faixa entre $\mathrm{R} \$ 100$ e $\mathrm{R} \$$ 300 por tonelada, e estimou-se o dano causada pelas infestantes (DE) entre $\mathrm{R} \$ 10$ e $\mathrm{R} \$ 300$ por hectare.

\section{RESULTADOS E DISCUSSÃO}

Não ocorreram sintomas evidentes de injúria nas plantas de milho quando tratadas com nicosulfuron no estádio de desenvolvimento $\mathrm{V}_{3}$, para ambas as doses aplicadas. Quando os tratamentos foram realizados nos estádios $\mathrm{V}_{6}$ e $\mathrm{V}_{9}$, coincidindo com a fase de diferenciação e desenvolvimento inicial da inflorescência feminina, que, segundo BABA \& YAMAZAKI, (1996) varia entre $V_{5}$ e $V_{10}$, observou-se que as plantas apresentaram má formação de espigas, com constrição do diâmetro do ráquis, falhas na formação de grãos e com grãos mal formados na região onde ocorreu constrição.

Independente dos estádios de desenvolvimento da cultura em que foi aplicado, não houve efeito de nicosulfuron nas variáveis estatura de planta, número de plantas sem espigas e espigas por planta. A estatura média das plantas foi de $187 \mathrm{~cm}$, o número médio de espigas foi de 1,01 por planta e, em média, 7,3\% das plantas não produziram espigas. DAMIÃO FILHO et al. (1996) verificaram redução na estatura de alguns híbridos de milho submetidos a tratamentos com nicosulfuron nos estádios $\mathrm{V}_{5}$ a $\mathrm{V}_{7}$.

Nicosulfuron, nas doses de 60 e $80 \mathrm{~g} \cdot \mathrm{ha}^{-1}$, reduziu o número de grãos por espiga no estádio de desenvolvimento $\mathrm{V}_{9}$, em relação aos demais estádios. O herbicida também reduziu o peso de grãos, quando aspergido nos estádios $\mathrm{V}_{6}$ e $\mathrm{V}_{9}$, em relação ao $\mathrm{V}_{3}$ (Tabela 1 ).

$\mathrm{Na}$ dose de $60 \mathrm{~g} \cdot \mathrm{ha}^{-1}$, nicosulfuron reduziu o rendimento de grãos do milho quando aplicado no estádio $\mathrm{V}_{9}$ em relação aos demais estádios. Já na dose de $80 \mathrm{~g} \cdot \mathrm{ha}^{-1}$ o rendimento de grãos foi afetado nos estádios $\mathrm{V}_{6} \mathrm{e} \mathrm{V}_{9}$, quando comparado à aplicação no estádio $\mathrm{V}_{3}$ (Tabela 1 ). $\mathrm{O}$ rendimento de grãos foi dependente da dose utilizada em $\mathrm{V}_{6}$ e $\mathrm{V}_{9}$, mas não foi afetado pelo herbicida quando aspergido em plantas no estádio de desenvolvimento $V_{3}$ (Tabela $1)$.

Especula-se que as plantas tratadas nos estádios mais avançados de desenvolvimento tenham interceptado e absorvido maior quantidade do herbicida do que aquelas pulverizadas em estádio precoce, devido à maior área foliar disponível durante as aplicações. Possivelmente, intensa atividade fotossintética nesses estádios de desenvolvimento contribuiu para a elevada translocação do herbicida das folhas aos meristemas. GALLAHER (1999) observou maior absorção e translocação do nicosulfuron com o aumento da luminosidade, acentuando a injúria no milho. $\mathrm{O}$ 
Tabela 1 - Número de grãos por espiga, peso de mil grãos e rendimento de grãos de milho submetido à aplicação de nicosulfuron em três doses e em três estádios de desenvolvimento vegetativo do milho. EEA/UFRGS, Eldorado do Sul, RS, 1998/99.

\begin{tabular}{|c|c|c|c|}
\hline \multirow[b]{2}{*}{ Doses $\left(\mathrm{g} \cdot \mathrm{ha}^{-1}\right)$} & \multicolumn{3}{|c|}{ Estádios de desenvolvimento } \\
\hline & $\mathrm{V}_{3}{ }^{\mathrm{a}}$ & $\mathrm{V}_{6}$ & $\mathrm{~V}_{9}$ \\
\hline & \multicolumn{3}{|c|}{ Grãos por espiga } \\
\hline 0 & $437 A^{b}$ & $462 \mathrm{~A}$ & $460 \mathrm{~A}$ \\
\hline 60 & $438 \mathrm{~A}$ & $422 \mathrm{~A}$ & $397 \mathrm{~B}$ \\
\hline 80 & $421 \mathrm{~A}$ & $404 \mathrm{~A}$ & $363 \mathrm{~B}$ \\
\hline \multirow[t]{2}{*}{$\mathrm{CV}(\%)$} & -------- & $8,7-$ & ------- \\
\hline & \multicolumn{3}{|c|}{ Peso de mil grãos (g) } \\
\hline 0 & $320 \mathrm{~A}$ & $317 \mathrm{~A}$ & $315 \mathrm{~A}$ \\
\hline 60 & $319 \mathrm{~A}$ & $287 \mathrm{~B}$ & $285 \mathrm{~B}$ \\
\hline 80 & $315 \mathrm{~A}$ & $268 \mathrm{~B}$ & $248 \mathrm{~B}$ \\
\hline \multirow[t]{2}{*}{$\mathrm{CV}(\%)$} & -------. & --- 9,4 - & --------- \\
\hline & \multicolumn{3}{|c|}{ Rendimento de grãos (kg.há $\left.{ }^{-1}\right)$} \\
\hline 0 & $9320 \mathrm{~A}$ & $9245 \mathrm{~A}$ & $9283 \mathrm{~A}$ \\
\hline 60 & $9119 \mathrm{~A}$ & $8417 \mathrm{~A}$ & $7647 \mathrm{~B}$ \\
\hline 80 & $8984 \mathrm{~A}$ & $7130 \mathrm{~B}$ & $6855 \mathrm{~B}$ \\
\hline $\mathrm{CV}(\%)$ & \multicolumn{3}{|c|}{ - } \\
\hline
\end{tabular}

${ }^{a}$ Número de folhas completamente expandidas (3, 6 e 9).

${ }^{\mathrm{b}}$ Médias nas linhas não seguidas pela mesma letra diferem entre si pelo teste de Tukey em nível de $5 \%$ de probabilidade.

mesmo autor verificou que o movimento do nicosulfuron para regiões meristemáticas contribuiu para a alta atividade do herbicida, porque a ALS é mais ativa nos tecidos em desenvolvimento.

O nicosulfuron é translocado no interior dos vegetais através dos vasos do floema, juntamente com carboidratos formados na fotossíntese, principalmente a sacarose. Plantas mais desenvolvidas apresentam maior área foliar fotossinteticamente ativa e produzem maior quantidade de fotoassimilados, consequentemente, o transporte destes produtos das folhas até as regiões de demanda da planta é mais intenso. Assim, o herbicida absorvido teria sido translocado com maior intensidade nas plantas mais desenvolvidas, atingindo os locais de ação antes de ser metabolizado pelas plantas de milho, causando injúria nas espigas durante a diferenciação floral. BABA \& YAMAZAKI (1996) relatam que a diferenciação das espigas de milho normalmente ocorre entre os estádios $V_{5}$ e $V_{10}$. Isso explicaria as deformações ocorridas nas espigas e a redução do peso e do número de grãos formados nas plantas tratadas com nicosulfuron a partir do estádio de seis folhas expandidas.

Plantas que receberam o nicosulfuron no estádio de desenvolvimento $\mathrm{V}_{3}$ não apresentaram sintomas de injúria nas espigas, provavelmente por anteceder o início da diferenciação das inflorescências, de modo que a ação do herbicida não teria afetado estas estruturas. Além disso, como comentado anteriormente, nesta fase, provavelmente as plantas absorveram menor quantidade do herbicida devido à sua menor área foliar. Outros estudos mostram que nos estádios iniciais de desenvolvimento, plantas de milho apresentam maior capacidade de metabolização do nicosulfuron do que nos estádios avançados de desenvolvimento vegetativo (McMULLAN \& BLACKSHAW, 1995; SWANTON et al., 1996; FAHL \& CARELLI, 1997).

Os resultados obtidos neste estudo indicam que a injúria causada pelo nicosulfuron, nas doses de 60 e $80 \mathrm{~g} . \mathrm{ha}^{-1}$, reduziu o rendimento de grãos do milho na ordem de 9 e $23 \%$ em relação à testemunha não tratada, quando aplicado no estádio de desenvolvimento $\mathrm{V}_{6}$; e, em 17 e $26 \%$ quando aplicado no estádio $\mathrm{V}_{9}$, respectivamente (Tabela 1). Portanto, a aplicação deste herbicida para controle de plantas daninhas em lavouras de milho quando a cultura se encontrar nos estádios de desenvolvimento a partir de seis folhas expandidas deverá ser feita com cautela, utilizando-se doses de acordo com a infestação de plantas daninhas presentes na lavoura.

As declividades das retas obtidas nas regressões entre dose e rendimento de grãos da cultura foram: $2,51 \times 10^{-3}$ e $3,18 \times 10^{-3}$, quando o herbicida foi aplicado nos estádios de desenvolvimento $V_{6}$ e $V_{9}$, respectivamente. Esses valores foram utilizados na Equação 1 e os resultados de DIE são apresentados na tabela 2 . Verifica-se que a dose máxima diminui com o aumento do preço do milho e aumenta à medida que cresce o dano causado pelas ervas (Tabela 2).

$O$ aumento na infestação de ervas intensifica o impacto sobre a produtividade da cultura, reduzindo o lucro obtido com a produção, de acordo com o preço da cultura na referida safra. Isso justifica o aumento da dose, no máximo até o ponto em que a redução do lucro, provocada pela injúria da dose aplicada, seja igual ao dano econômico causado pelas ervas sobre a cultura. Contudo, quando a infestação de plantas daninhas estiver próxima do limite de dano econômica (baixa infestação), o dano econômico das ervas será baixo e, nesse caso, maior poderá ser o impacto da injúria do herbicida no rendimento econômico da cultura (Tabela 2).

Observa-se que, em situações nas quais o dano das ervas é pequeno e/ou quando o preço do 
Tabela 2 - Dose de injúria econômica de nicosulfuron a ser utilizada na cultura do milho nos estádios de desenvolvimento $\mathrm{V}_{6}$ e $\mathrm{V}_{9}$. EEA/UFRGS, Eldorado do Sul, RS, 1998/99.

\begin{tabular}{|c|c|c|c|c|c|}
\hline \multirow{3}{*}{$\begin{array}{c}\text { Dano de infestantes } \\
\left(\mathrm{R} \$ . \mathrm{ha}^{-1}\right)\end{array}$} & \multicolumn{5}{|c|}{ Preço do milho $\left(\mathrm{R} \$ . \mathrm{t}^{-1}\right)$} \\
\hline & 100 & 150 & 200 & 250 & 300 \\
\hline & \multicolumn{5}{|c|}{ Estádio $\mathrm{V}_{6}{ }^{\mathrm{a}}$} \\
\hline 10 & 6 & 4 & 3 & 2 & 2 \\
\hline 50 & 28 & 19 & 14 & 11 & 9 \\
\hline 100 & 57 & 38 & 28 & 23 & 19 \\
\hline 150 & 85 & 57 & 43 & 34 & 28 \\
\hline 200 & 100 & 76 & 57 & 45 & 38 \\
\hline 250 & 100 & 95 & 71 & 57 & 47 \\
\hline \multirow[t]{2}{*}{300} & 100 & 100 & 85 & 68 & 57 \\
\hline & \multicolumn{5}{|c|}{ Estádio $\mathrm{V}_{9}{ }^{\mathrm{b}}$} \\
\hline 10 & 4 & 3 & 2 & 2 & 1 \\
\hline 50 & 22 & 15 & 11 & 9 & 7 \\
\hline 100 & 45 & 30 & 22 & 18 & 15 \\
\hline 150 & 67 & 45 & 34 & 27 & 22 \\
\hline 200 & 90 & 60 & 45 & 36 & 30 \\
\hline 250 & 100 & 75 & 56 & 45 & 37 \\
\hline 300 & 100 & 90 & 67 & 54 & 45 \\
\hline
\end{tabular}

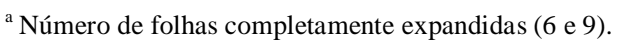

milho é alto, a dose máxima de dano econômico é bastante reduzida (Tabela 2). Provavelmente, nesses casos, a dose aplicada não alcançará controle adequado das plantas daninhas. Além disso, algumas espécies daninhas podem apresentar tolerância ao nicosulfuron quando a dose aplicada for inferior à dose recomendada pelo fabricante.

Misturas de nicosulfuron, em dose reduzida, com outros herbicidas que tenham pouco efeito sobre as plantas de milho, como por exemplo atrazine, poderiam ser uma alternativa para se obter controle satisfatório das plantas daninhas sem causar danos à cultura. Entretanto, a legislação brasileira só permite misturas de produtos no pulverizador quando as mesmas tenham sido registradas junto aos órgãos oficiais competentes.

\section{CONCLUSÕES}

A seletividade do nicosulfuron em milho diminui com o desenvolvimento da cultura além do estádio de seis folhas expandidas e com o incremento da dose além de $60 \mathrm{~g} \cdot \mathrm{ha}^{-1}$. A dose de injúria econômica, ou seja, a dose de nicosulfuron na qual o benefício do controle de infestantes se iguala à perda de rendimento de grãos devido a injúria à cultura, reduz-se com a diminuição do dano das infestantes e com o aumento do preço da cultura.

\section{REFERÊNCIAS BIBLIOGRÁFICAS}

ANDERSON, D.D., NISSEN, S.J., MARTIN, A.R., $\boldsymbol{e} \boldsymbol{t} \boldsymbol{a} \boldsymbol{l}$. Mechanism of primisulfuron resistance in a shattercane (Sorghum bicolor) biotype. Weed Science, Lawrence, v.46, n.1, p.158-162, 1998.

ASHTON, F.M., MONACO, T.D. Weed science: principles and practices. 3 ed. New York: J. Wiley, 1991. 272p.

BABA, T., YAMAZAKI, K. Effects of phase transition on the development of lateral buds in maize. Crop Science, Madison, v.36, n.10, p.1574-1579, 1996.

BRUCE, J.A., CAREY, J.B., PENNER, D., et al. Effect of growth stage and environment on foliar absorption, translocation, metabolism, and activity of nicosulfuron in quackgrass (Elytrigia repens). Weed Science, Champaign, v.44, n.3, p.447-454, 1996.

CAREY, J.B., PENNER, D., KELLS, J.J. Physiological basis for nicosulfuron and primisulfuron selectivity in five plant species. Weed Science, Lawrence, v.45, n.1, p.22-30, 1997.

DAMIÃO FILHO, C.F., MÔRO, F.V., TAVEIRA, L.R. Respostas de híbridos de milho ao nicosulfuron. 1 - Aspectos biológicos e da produção. Planta Daninha, Londrina, v.14, n.1, p.3-13, 1996.

DEEN, W.A., WEERSINK, A., TURVEY, C.G., et al. Weed control decision rules uncertainty. Annual Review Agricultural Economic, Palo Alto, v.15, n.1, p.39-50, 1993.

FAHL, J.L., CARELLI, M.L. Eficiência do nicosulfuron no controle de capim massambará na cultura do milho. Planta Daninha, Londrina, v.15, n.1, p.46-52, 1997.

FONNE-PFISTER, R., GAUDIN, J., KREUZ, K., $\boldsymbol{e}$ t al . Hydroxylation of primisulfuron by inducible cytochrome $\mathrm{P}_{450}$ dependent monooxygenase system from maize. Pesticide Biochemistry Physiology, v.37, n.1, p.165-173, 1990.

GALLAHER, K. Absorption, translocation, and metabolism of primisulfuron and nicosulfuron in broadleaf signalgrass (Brachiaria platyphylla) and corn. Weed Science, Lawrence, v.47, n.1, p.8-12, 1999.

GubBigA, N.G., WORShAM, A.D., COBLE, H.D., $\boldsymbol{e} \boldsymbol{t}$ al. Effect of nicosulfuron on johnsongrass (Sorghum halepense) control and corn (Zea mays) performance. Weed Technology, Champaign, v.9, n.3, p.574-581, 1995.

McMULLAN, P.M., BLACKSHAW, R.E. Postemergence green foxtail (Setaria viridis) control in corn (Zea mays) in Western Canada. Weed Technology, Champaign, v.9, n.1, p.37-43, 1995.

MORTON, C.A., HARVEY, R.G. Sweet corn (Zea mays) hybrid tolerance to nicosulfuron. Weed Technology, Champaign, v.6, n.1, p.91-96, 1992.

OBRIGAWITCH, T.T., KENYON, W.H., KURATLE, H. Effect of application timing on rhizome johnsongrass (Sorghum halepense) control with DPX-V9360. Weed Science, Champaign, v.38, n.1, p.45-49, 1990. 
SIEGELIN, S.D. Timing of nicosulfuron and primisulfuron applications on corn (Zea mays L.) ear malformation. West Lafayette, 1993. 61p. Thesis (Master of Science in Weed Science) - Purdue University, 1993.

SPADER, V. Avaliação bioeconômica da interferência de Brachiaria plantaginea (Linl) Hitch. e de herbicidas na cultura do milho. Porto Alegre, 2000. 74p. Dissertação (Mestrado em Plantas Daninhas) - Universidade Federal do Rio Grande do Sul, 2000

SULLIVAN, J.O., BOUW, W.J. Sensitivity of processing sweet corn (Zea mays) cultivars to nicosulfuron/rimsulfuron
Canadian Journal of Plant Science, Ontario, v.41, n.1, p.151-154, 1997.

SWANTON, C.J., CHANDLER, K., ELMES, M.J., et al Postemergence control of annual grasses in corn (Zea mays) and two annual grass weeds. Weed Science, Champaign, v.44, n.2, p.219-223, 1996.

SWEETSER, P.B., SCHOW, G.S., HUTCHENSON, J.M Metabolism of chlorsulfuron by plants: biological basis for selectivity of a new herbicide for cereals. Pesticide Biochemistry Physiology, San Diego, CA, v.18, n.1, p.1823, 1982 .

Ciência Rural, v. 31, n. 6, 2001. 